\title{
RECOVERYKOAGULAN DARI SLUDGE WWTP PEMBANGKIT LISTRIK TENAGA UAP SEBAGAI ALTERNATIF PENGOLAHAN AIR LIMBAH SECARA KIMIA
}

\section{RECOVERY OF COAGULANT FROM WWTP SLUDGE STEAM POWER PLANTS AS AN ALTERNATIVE OF CHEMICAL WASTE WATER TREATMENT}

\author{
Adhi Setiawan, Ahmad Erlan Afiuddin, Qurrotul Aini, dan Tanti Utami Dewi \\ Program Studi Teknik Pengolahan Limbah, Politeknik Perkapalan Negeri Surabaya (PPNS) \\ Jl. Teknik Kimia Kampus ITS Sukolilo-Surabaya, Indonesia 60111 \\ Alamat Email: adhistw23@gmail.com
}

Diterima : 16-09-2018

Direvisi : 31-10-2018

Disetujui : 12-11-2018

\begin{abstract}
ABSTRAK
Proses koagulasi di wastewater treatment plant (WWTP) menghasilkan produk samping berupa residu (sludge) dalam jumlah besar serta belum dimanfaatkan secara optimal. Penelitian ini bertujuan untuk melakukan karakterisasi terhadap s/udge, mempelajari pengaruh konsentrasi asam klorida pada proses recoveri koagulan, serta menganalisis pengaruh dosis koagulan hasil recovery s/udge terhadap removal TSS, Zn, dan Fe. Proses recovery koagulan dilakukan dengan metode pengasaman menggunakan $\mathrm{HCl}$ pada konsentrasi 1-3 N. Hasil analisis gravimetric menunjukkan bahwa sludge kering memilki kandungan Fe sebesar 22,94\% wt. Peningkatan konsentrasi $\mathrm{HCl}$ menyebabkan peningkatan konsentrasi Fe yang terecovery. Proses asidifikasi sludge dengan $\mathrm{HCl} 3 \mathrm{~N}$ menghasilkan SRP dengan kandungan koagulan Fe yang tertinggi yakni sebesar $52,3 \mathrm{mg} / \mathrm{L}$. Hasil jar tes menunjukkan bahwa penambahan Sludge Reagent Product (SRP) $3 \mathrm{~N}$ pada dosis $10 \mathrm{~mL} / \mathrm{L}$ menghasilkan konsentrasi TSS dan Zn paling rendah yakni sebesar $34 \mathrm{mg} / \mathrm{L}$ dan 0,01 mg/L. Besarnya persen removal TSS dan Zn pada SRP $3 \mathrm{~N}$ dosis $10 \mathrm{~mL} / \mathrm{L}$ masing-masing sebesar $79,4 \%$ dan $96,5 \%$. Persen removal Fe tertinggi diperoleh pada SRP $1 \mathrm{~N}$ dengan dosis $4 \mathrm{~mL} / \mathrm{L}$ dengan nilai sebesar 97,5. Jenis dan dosis SRP yang direkomendasikan untuk menurunkan TSS, Fe, dan Zn antara lain semua dosis SRP HCl $1 \mathrm{~N}, \mathrm{SRP} \mathrm{HCl} 1,5 \mathrm{~N}$ dan SRP HCl $2 \mathrm{~N}$ pada dosis $4 \mathrm{~mL} / \mathrm{L}$.
\end{abstract}

Keywords: koagulasi, koagulan, recovery lumpur, asidifikasi.

\begin{abstract}
The coagulation process in the wastewater treatment plant (WWTP) produces residue (sludge) by products in large quantities and has not been used optimally. This study aims to characterize the sludge, analyze the effect of the concentration of hydrochloric acid on the coagulant recovery process, and analyze the effect of coagulant dosage from recovery sludge on the removal of TSS, Zn, and Fe. The coagulant recovery process used acidification using $\mathrm{HCl}$ at a concentration of $1-3 \mathrm{~N}$. The results of gravimetric analysis showed that dry sludge had Fe content of $22,94 \%$ wt\%. Increasing the concentration of $\mathrm{HCl}$ causes an increase in the concentration of recovered Fe. The acidification concentration with $\mathrm{HCl} 3 \mathrm{~N}$ produced the SRP with highest Fe coagulant content of $52.3 \mathrm{mg} / \mathrm{L}$. Jar test results showed that the addition of SRP $3 \mathrm{~N}$ at a dose of $10 \mathrm{~mL} / \mathrm{L}$ resulted in the lowest concentrations of TSS and $Z n$ at $34 \mathrm{mg} / \mathrm{L}$ and $0.01 \mathrm{mg} / \mathrm{L}$ respectively. The percent removal of TSS and $Z n$ at SRP $3 \mathrm{~N}$ with a dose of $10 \mathrm{ml} / /$ were $79.4 \%$ and $96.5 \%$ respectively. The highest percent removal of Fe was obtained at SRP $1 \mathrm{~N}$ at a dose of $4 \mathrm{~mL} / \mathrm{L}$ with a value of 97.5. SRP types and doses recommended for reducing TSS, Fe, and Zn include all SRP HCl $1 \mathrm{~N}$ with all doses, SRP HCl $1.5 \mathrm{~N}$ and SRP HCl $2 \mathrm{~N}$ at a dose of $4 \mathrm{~mL} / \mathrm{L}$.
\end{abstract}

Keywords: coagulation, coagulant, sludge recovery, acidification.

126 Adhi Setiawan, Ahmad Erlan Afiudin, Qorrotul Aini, Tanti Utami Dewi Recovery Koagulan dari Sludge WWTP Pembangkit Listrik Tenaga Uap Sebagai Alternatif Pengolah Air Limbah secara Kimia 


\section{PENDAHULUAN}

D roses pengolahan air limbah pada umumnya melibatkan proses koagulasi, flokulasi, sedimentasi, filtrasi, dan desinfeksi dalam suatu rangkaian proses yang mengolah air limbah hasil kegiatan industri maupun domestik sehingga layak dibuang ke lingkungan. Proses koagulasi merupakan tahapan penting proses pengolahan air limbah atau air permukaan yang bertujuan untuk mendestabilisasi partikel koloid yang menyebabkan kekeruhan pada air. Proses koagulasi dapat dianggap sebagai salah satu proses fisikokimia yang paling umum digunakan dalam pengolahan air karena mudah dioperasikan serta memilki desain relatif sederhana (Teh dan Wu, 2014:1603). Partikel koloid yang terdestabilisasi akan teraglomerasi membentuk partikel berukuran lebih besar sehingga mudah mengalami pengendapan dalam proses sedimentasi atau mudah dipisahkan dalam serangkaian proses filtrasi (Teh et al., 2016: 4367).

Proses koagulasi-flokulasi merupakan proses penting dalam pengolahan air limbah maupun air minum. Dalam proses koagulasi, partikel koloid yang tersuspensi di dalam air terdestabilisasi setelah mengalami penetralan muatan permukaan akibat penambahan koagulan. Proses koagulasi-flokulasi menghasilkan aggregat partikel yang tidak stabil dan mengendap dalam bentuk sludge (Wei et al., 2018: 608). Jumlah dari s/udge yang dihasilkan meningkat seiring dengan meningkatkan kandungan bahan organik dan koloidal anorganik di dalam air limbah, jumlah air limbah yang diolah, serta jumlah industri penghasil air limbah (Christensen et al., 2015: 14). Sejumlah data menunjukkan bahwa jumlah sludge yang dihasilkan dari pengolahan air limbah cukup besar akibat tingkat kebutuhan koagulan yang tinggi. Di negara Inggris setiap tahun menghasilkan 0,18 juta ton s/udge dengan konsumsi koagulan mencapai 0,33 juta ton. Bahkan di Negara Amerika konsumsi alum mencapai 730 juta ton/tahun sedangkan di Jepang konsumsi alum setiap tahun mencapai 0,30 juta ton/tahun (Keeley et al., 2016: 502). Badan Pusat Statistik (2014) melaporkan bahwa konsumsi koagulan alum di Indonesia rata-rata mencapai 0,32 juta ton/tahun.

Sludge yang terbentuk dari garam anorganik seperti alum atau ferri memiliki sifat kompresibiltas yang rendah, struktur yang padat, serta memiliki kandungan padatan yang tinggi (Chen et al., 2015: 36) . Meskipun sludge yang terbentuk mudah mengedap, namun hampir tidak mungkin pengeringan dilakukan tanpa proses pretreatment. Proses pretreatment sludge pada umumnya dilakukan dengan dewatering dan pengeringan (drying) untuk mengurangi kandungan air di dalam s/udge sehingga menghasilkan bagian padat sekitar $20 \%$ dari massa sludge. Proses dewatering dapat berlangsung lebih cepat namun membutuhkan energi yang relatif besar untuk menekan filter sedangkan pengeringan dengan energi matahari lebih ekonomis namun membutuhkan aktu yang relatif lama (Wei et al., 2018: 608).

Beberapa jenis koagulan kimia dari garam aluminium seperti $\mathrm{Al}_{2}\left(\mathrm{SO}_{4}\right)_{3} .18 \mathrm{H}_{2} \mathrm{O}$ atau garam besi $\left(\mathrm{FeCl}_{3} .6 \mathrm{H}_{2} \mathrm{O}, \mathrm{FeCl}_{2}, \mathrm{FeSO}_{4} .7 \mathrm{H}_{2} \mathrm{O}\right)$ seringkali digunakan sebagai koagulan (Sales et al., 2011: 2793). Aluminium sulfat atau alum $\left(\mathrm{Al}_{2}\left(\mathrm{SO}_{4}\right)_{3} \cdot 18 \mathrm{H}_{2} \mathrm{O}\right)$ seringkali digunakan sebagai koagulan di dunia untuk mengolah pengolahan air minum. Alum akan terhidrolisisis menghasilkan aluminium hidroksida. Lumpur koloidal serta suspensi pengotor yang ada di dalam air dapat dipisahkan melalui penetralan muatan maupun adsorpsi pada permukaan endapan besi hidroksida atau aluminium hidroksida (Trinh dan Kang, 2011: 1132). Berdasarkan fakta menunjukkan bahwa proses koagulasi dengan koagulan garam aluminium atau besi menghasilkan residu sludge (lumpur) dalam jumlah besar serta mengandung Al atau Fe yang dapat direcovery kembali menjadi bahan koagulan (Suman et al., 2018: 215).

Beberapa Negara India dan Zimbabwe pembuangan limbah lumpur hasil proses koagulasi dibuang secara langsung di sekitar instalasi pengolahan air limbah (Ahmad et al., 2016; Muisa et al., 2011). Hal tersebut tidak memberikan solusi secara tepat bahkan berpotensi menyebabkan pembentukan endapan lumpur yang tidak diinginkan serta dapat menyebabkan kontaminasi pada badan air penerima akibat produk kimia yang digunakan 
selama proses pengolahan air limbah. Beberapa alternatif yang seringkali digunakan dalam menangani permasalah limbah lumpur antara lain dengan insenerasi atau landfilling dengan pertimbangan bahwa limbah tersebut beracun (Shak dan Wu, 2015). Di Negara Indonesia limbah sludge (lumpur) dari instalasi pengolahan air limbah dikelompokkan sebagai limbah B3 karena mengandung logam berat serta pelarut organik sehingga memerlukan penanganan khusus dalam proses pengolahannya (Sari et al., 2014: 240). Oleh karena itu, recovery koagulan dapat menjadi alternatif mengurangi penggunaan bahan kimia serta meminimalisir dampak negatif yang ditimbulkan terhadap lingkungan.

Biaya pembuangan limbah lumpur merupakan faktor utama yang menentukan komponen dari biaya operasional instalasi pengolahan air limbah. Sekitar 30-50\% biaya operasional per tahun dialokasikan untuk proses dewatering sludge. Sludge atau lumpur hasil koagulasi memiliki mengandung bahan organik dan logam (Fe atau $\mathrm{Al}$ ) yang dapat diperoleh melalui proses recovery sehingga dapat menjadi cara yang efektif untuk mengurangi volume lumpur serta menghemat penggunaan koagulan. Metode recovery koagulan dapat dilakukan dengan empat cara antara lain pengasaman, pembasaan, pertukaran ion, dan membran (Xu et al., 2005; Xu et al., 2009).

Beberapa peneliti telah melaporkan bahwa limbah s/udge koagulasi dapat dimanfaatkan kembali menjadi bahan koagulan dengan merecovery kandungan $\mathrm{Al}$ atau $\mathrm{Fe}$ di dalam lumpur. Mirwan (2012: 78) dalam penelitiannya melakukan recovery kandungan Al di dalam limbah lumpur PDAM Intan Banjar dengan menggunakan larutan $\mathrm{NaOH}$. Hasil penelitian tersebut menghasilkan tawas cair yang dapat digunakan sebagai bahan perjernih air sungai Martapura. Moerdiyanti et al. (2014: 2) melakukan penelitian tentang recovery aluminium dari limbah padat lumpur PDAM Kota Pontianak menggunakan $\mathrm{H}_{2} \mathrm{SO}_{4}$ sebagai koagulan dalam pengolahan air bersih. Nair dan Ahammed (2015: 273) melaporkan bahwa limbah lumpur dari koagulan poli aluminium klorida dapat digunakan sebagai koagulan pada proses post treatment reaktor upflow anerobic sludge blanket (UASB) untuk mengolah air limbah perkotaan. Metode pertukaran ion (ion exchange) cukup efektif dalam memisahkan kandungan organik dan logam di dalam lumpur namun dari aspek ekonomi penggunaan pertukaran ion cukup mahal (Prakash dan Sengupta, 2003). Ahmad et al. (2016: 610) telah melakukan recovery koagulan dari sludge berbasis alum yang dihasilkan pada proses koagulasi-flokulasi pengolahan air permukaan. Proses recovery dilakukan pada limbah lumpur dengan menggunakan larutan asam sulfat pada pada konsentrasi $2,5 \mathrm{~N}$ dengan $\mathrm{pH} 1$. Hasil penelitian menunjukkan bahwa penggunaan koagulan hasil recovery cukup efektif dalam meremoval turbiditi air dari Sungai Yamuna pada dosis $12 \mathrm{~mL} / \mathrm{L}$ pada $\mathrm{pH} 2$.

Penggunaan koagulan $\mathrm{FeCl}_{3}$ di dalam proses koagulasi air limbah juga menghasilkan s/udge dalam jumlah yang relatif besar sehingga berpotensi menimbulkan pencemaran terhadap lingkungan. Oleh karena itu, diperlukan suatu metode untuk merecovery kandungan koagulan Fe di dalam lumpur sehingga dapat dimanfaatkan kembali di dalam proses koagulasi. Proses pengasaman merupakan salah satu metode recovery koagulan yang relatif murah serta memiliki efisiensi yang lebih tinggi dibandingkan dengan metode pembasaan (alkalisasi) (Huang et al., 2010: 1165). Penelitian difokuskan untuk melakukan karakterisasi s/udge, mempelajari pengaruh konsentrasi $\mathrm{HCl}$ pada proses recovery koagulan, serta menganalisis pengaruh dosis koagulan hasil recovery sludge terhadap removal TSS, Zn, dan Fe yang terlarut. Limbah lumpur yang direcovery tersebut dihasilkan dalam proses koagulasi unit Waste Water Treatment Plant (WWTP) pembangkit listrik tenaga uap (PLTU). Dengan pemanfaatan limbah lumpur sebagai bahan koagulan sangat diperlukan untuk meminimalisir lumpur yang dihasilkan serta meminimalisir penggunaan koagulan kimia $\mathrm{FeCl}_{3}$. 


\section{METODELOGI PENELITIAN \\ Alat dan Bahan}

Alat yang digunakan dalam penelitian ini terdiri atas oven, neraca analitik, $\mathrm{pH}$ meter, hot plate, peralatan jar tes, Spektrofotometer UV-Vis (Hach DR 3900), Scanning Electron Microscope-Energy Dispersion X-Ray (SEM-EDX) Phenom Dekstop ProX, XRD (X-ray Diffraction) X'Pert RINT $2200 \mathrm{~V}$ Philiph CuKa $(\lambda=1,5418 \AA)$. Bahan yang digunakan pada penelitian terdiri dari lumpur atau sludge dari WWTP, air limbah inlet WWTP, kertas saring dengan ukuran pori 1,5 $\mu \mathrm{m}$, sikloheksanon (Merck), larutan $\mathrm{HCl} 37 \%$ (Merck), reagen ZincoVer dan FerroVer (Hach Company). Sludge dihasilkan dari proses koagulasi-flokulasi di unit waste water treatment plant (WWTP) yang menggunakan koagulan jenis $\mathrm{FeCl}_{3} \cdot 6 \mathrm{H}_{2} \mathrm{O}$.

\section{Karakterisasi Sludge}

Penelitian ini menggunakan limbah s/udgeyang dihasilkan dari proses koagulasi-flokulasi di WTTP PLTU dengan koagulan $\mathrm{FeCl}_{3} \cdot 6 \mathrm{H}_{2} \mathrm{O}$. Sampel s/udge (lumpur) yang diteliti diambil dari unit sedimentasi WWTP yang telah mengalami pengendapan selama dua jam untuk memisahkan lumpur dan air yang telah jernih. Lumpur yang mengendap selanjutnya dipisahkan dan dibilas dengan aquadest untuk menghilangkan pengotor yang ikut terbawa di dalam lumpur. Sludge selanjutnya disaring dan dikeringkan di dalam oven pada suhu $100^{\circ} \mathrm{C}$ selama tiga jam sehingga menghasilkan sludge kering. Sludge kering selanjutnya dianalisis morfologinya menggunakan SEM. Kristalinitas s/udgekering dianalisis dengam XRD sedangkan kandungan logam Fe di dalam s/udge dianalisis menggunakan metode gravimetri.

\section{Proses Recovery Koagulan}

Sludge (lumpur) yang telah dikeringkan dilarutkan ke dalam $100 \mathrm{ml}$ aquadest dengan konsentrasi $1 \%$ wt. Pada $100 \mathrm{~mL}$ Larutan yang mengandung s/udge tersebut ditambahkan 36 $\mathrm{ml}$ larutan $\mathrm{HCl}$. Tujuan penambahan larutan $\mathrm{HCl}$ yaitu melarutkan kandungan Fe yang terdapat di dalam sludge menghasilkan koagulan $\mathrm{FeCl}_{3}$. Variasi konsentrasi larutan $\mathrm{HCl}$ yang ditambahkan pada larutan sludge antara lain sebesar $1 \mathrm{~N} ; 1,5 \mathrm{~N} ; 2 \mathrm{~N} ; 2,5 \mathrm{~N}$; dan $3 \mathrm{~N}$. Proses pengasaman tersebut disertai pengadukan dan pemanasan dengan hot plate yang dioperasikan pada $100 \mathrm{rpm}$ dan suhu $50^{\circ} \mathrm{C}$ selama tiga jam. Setelah proses pengasaman selesai dilanjutkan dengan penyaringan untuk memisahkan filtrat dengan partikel lumpur. Filtrat yang mengandung koagulan hasil recovery sludge (lumpur) mengandung koagulan $\mathrm{FeCl}_{3}$ disebut dengan sludge reagent product (SRP) yang digunakan sebagai alternatif pengganti koagulan kimia dalam proses koagulasi.

\section{Evaluasi Kinerja Produk Koagulan}

Kinerja dari koagulan sludge reagent product(SRP) dalam menurunkan kandungan TSS, $\mathrm{Fe}$, dan Zn di dalam air limbah diuji dengan menggunakan metode jar test. Volume air limbah yang digunakan pada jar test sebesar $1 \mathrm{~L}$ dengan disertai proses pengadukan. Dosis koagulan SRP yang digunakan pada saat jar tes yaitu 4, 6, 8, dan $10 \mathrm{~mL}$. Pengadukan cepat dilakukan selama 2 menit pada $100 \mathrm{rpm}$ dan selanjutnya dilanjutkan dengan pengadukan lambat pada 40 rpm selama 30 menit. Sample air limbah yang telah diaduk selanjutnya didiamkan selama 20 menit untuk mengendapkan flok yang telah terbentuk.

Air limbah sebelum dan setelah dilakukan jar tes diuji parameternya yang meliputi total padatan tersuspensi (TSS), kandungan Fe, dan Zn yang terlarut. Pengujian parameter TSS menggunakan metode gravimetri berdasarkan SNI 06-6989.3-2004.

Konsentrasi Fe dan $\mathrm{Zn}$ yang terlarut dianalisis dengan menggunakan spektrofotometer UV-Vis. Prosedur pengujian Fe dan Zn yang terlarut berdasarkan Hach Handbook of Water analisis dari Hach Chemical Company (2010). Pada pengujian kadar Zn yang dilakukan dengan 
menuangkan sebanyak $50 \mathrm{~mL}$ air limbah ke dalam tabung pencampur (mixing cylinder). Pada air limbah tersebut ditambahkan dengan 20 mg reagen ZincoVer (Hach Company) dan tabung silinder dikocok secara perlahan agar reagen dapat larut seluruhnya. Reagen ZincoVer mengandung senyawa sianida yang dapat bereaksi dengan logam $\mathrm{Zn}$ dan logam lain membentuk senyawa kompleks. Larutan yang telah diiberi dengan reagen ZincoVer selanjutkan dibagi menjadi dua bagian yang sama yakni sebagai blanko dan sampel. Larutan sampel selanjutnya ditambahkan dengan sikloheksanon sebanyak 0,5 mL dan dibiarkan selama 3 menit hingga warna larutan menjadi kebiruan (indikasi mengandung $\mathrm{Zn}$ ). Penambahkan sikloheksanon bertujuan untuk pelepasan ion Zn secara selektif. Zn selanjutnya bereaksi dengan indikator 2-karboksi-2'-hidroksi-5'-sulfoformasil benzene menghasilkan spesies yang warna biru. Larutan sample selanjutnya dianalisis dengan spektrofotometer pada panjang gelombang $620 \mathrm{~nm}$.

Analisis kandungan Fe di dalam air limbah dilakukan dengan menambahkan reagen FerroVer (Hach Company) sebanyak $20 \mathrm{mg}$ pada $25 \mathrm{~mL}$ air limbah di dalam silinder pencampur. Larutan selanjutnya dikocok secara perlahan dan dibiarkan selama 5 menit hingga terjadi perubahan warna larutan menjadi orange (indikasi mengandung Fe). Reagen FerroVer mengandung 1,10-Phenantrolin yang dapat mengikat ion $\mathrm{Fe}$ yang terlarut menghasilkan senyawa kompleks yang berwarna orange. Pembuatan blanko pada analisis Fe dilakukan dengan menggunakan sampel air limbah tanpa penambahan reagen FerroVer. Larutan sampel selanjutnya dapat dianalisis dengan spektrofotometer pada panjang gelombang $510 \mathrm{~nm}$.

\section{HASIL DAN PEMBAHASAN \\ Karakterisasi Sludge}

Komposisi s/udge yang hasil proses koagulasi ditentukan dengan EDX sebagaimana ditunjukkan pada Gambar 1. Spektra EDX tersebut mendeteksi sejumlah unsur-unsur yang terkandung di dalam sludge sebagaimana komposisinya disajikan pada Tabel 1 . Hasil analisis SEM-EDX menunjukkan bahwa sludge atau lumpur memiliki kandungan unsur Fe yang dapat direcovery kembali menghasilkan koagulan $\mathrm{FeCl}_{3}$. Hasil analisis dengan menggunakan metode gravimetri menunjukkan bahwa s/udge kering hasil proses koagulasi memiliki kandungan logam Fe sebesar 22,94\% wt.

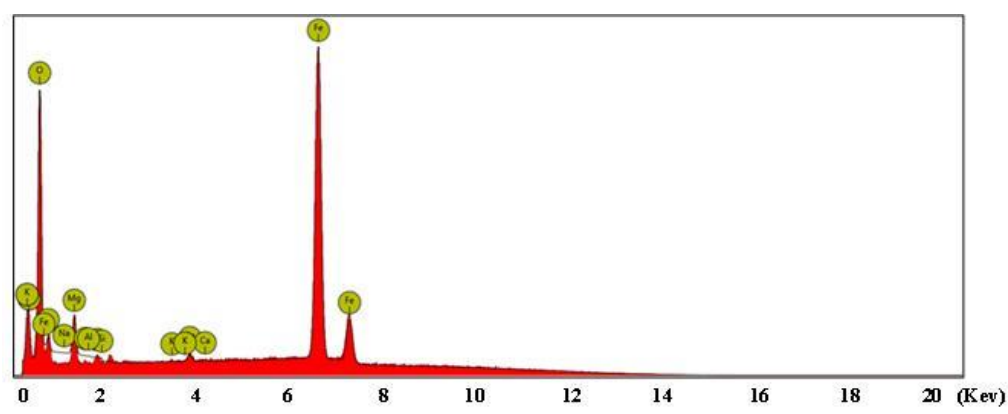

Gambar 1. Spektra EDX dari Limbah Sludge

Selain itu, pada analisis EDX terdeteksi beberapa unsur seperti $\mathrm{Si}, \mathrm{Mg}, \mathrm{Ca}$, dan $\mathrm{K}$ dalam jumlah yang relatif kecil. Hal tersebut kemungkinan dapat disebabkan adanya pengotor di dalam air limbah atau koagulan yang digunakan pada proses koagulasi air limbah (Suman et al., 2018; Ahmad et al., 2016). Gambar 2 menunjukkan bahwa SEM dari partikel s/udge. Pengujian SEM bertujuan untuk mengarakterisasi bentu dan morfologi dari partikel s/udge. Hasil analisis menunjukkan bahwa partikel s/udge memilkik morfologi berbentuk butiran dengan ukuran rata-rata $14,2 \mu \mathrm{m}$ serta topografi permukaan yang tidak teratur. 
Tabel 1. Hasil Analisis EDX Sludge dari WWTP PLTU

\begin{tabular}{lc}
\hline \multicolumn{1}{c}{ Jenis unsur } & Kadar $(\%$ wt) \\
\hline O (oksigen) & 25,74 \\
Fe (besi) & 69,29 \\
Mg (magnesium) & 4,41 \\
Ca (kalsium) & 0,47 \\
Si (silikon) & 0,05 \\
K (kalium) & 0,03 \\
\hline
\end{tabular}

Gambar 3 menunjukkan bahwa struktur kristal dari limbah sludge berbentuk kristal dengan komposisi fase yang didominasi oleh fase $\mathrm{Fe}(\mathrm{OH})_{3}$ dan $\mathrm{Fe}_{2} \mathrm{O}_{3}$. Analisis puncak dari kristal $\mathrm{Fe}(\mathrm{OH})_{3}$ dan $\mathrm{Fe}_{2} \mathrm{O}_{3}$ masing-masing mengacu pada standar ICSD 00-022-0346 dan ICSD 00-033-0664. Kedua senyawa tersebut terbentuk dari proses hidrolisis senyawa $\mathrm{FeCl}_{3}$ menghasilkan $\mathrm{Fe}(\mathrm{OH})_{3}$ dan $\mathrm{Fe}_{2} \mathrm{O}_{3}$. Hasil penelitian yang sama dilaporkan oleh Suman et al. (2018: 216) yang mendeteksi adanya kandungan $\mathrm{Fe}(\mathrm{OH})_{3}$ dan $\mathrm{Fe}_{2} \mathrm{O}_{3}$ pada saat melakukan karakterisasi XRD limbah lumpur hasil proses koagulasi dengan koagulan berbasis Fe maupun Al.

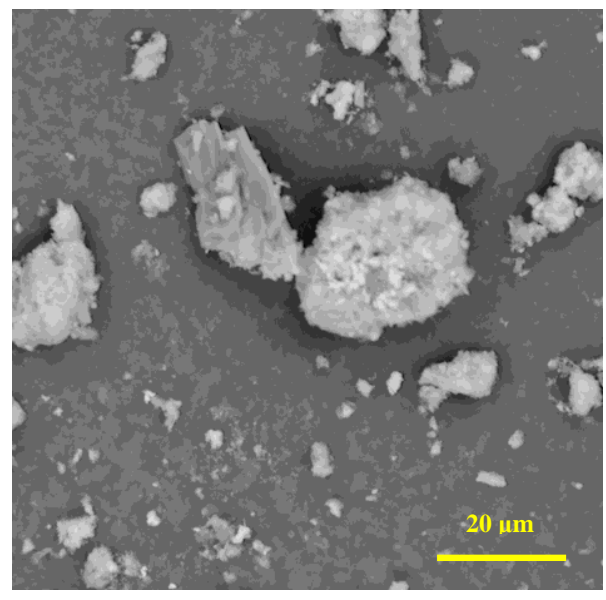

Gambar 2. SEM dari Limbah Sludge

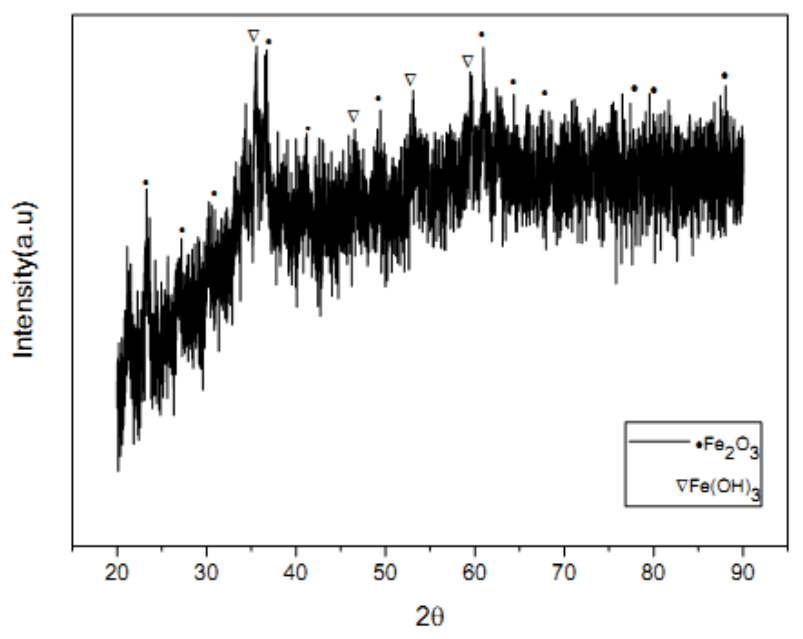

Gambar 3. XRD dari Limbah Sludge 


\section{Kinerja koagulan SRP}

Hasil Uji parameter TSS, Fe, dan Zn di dalam air limbah setelah dilakukan jar test dengan koagulan SRP akan dibandingkan dengan baku mutu limbah industri berdasarkan Kepmen LHK No. 04.29.12 Tahun 2014 Tentang Ijin Pembuangan Air Limbah Ke laut dari Kegiatan PLTU dan PLTGU di Selat Madura oleh PT. PJB Gresik. Hasil uji kandungan TSS, Fe, dan Zn pada inlet WWTP PLTU sebagaimana disajikan pada Tabel 2.

Tabel 2. Hasil Analisis Air Limbah Inlet WWTP PLTU

\begin{tabular}{lccc}
\hline Parameter & Satuan & Hasil analisa & Baku mutu \\
\hline TSS & $\mathrm{mg} / \mathrm{L}$ & 165 & 100 \\
$\mathrm{Fe}$ & $\mathrm{mg} / \mathrm{L}$ & 5,41 & 3 \\
$\mathrm{Zn}$ & $\mathrm{mg} / \mathrm{L}$ & 0,315 & 1 \\
\hline
\end{tabular}

Berdasarkan hasil uji karakteristik air limbah menunjukkan bahwa parameter TSS, Fe masih melebihi baku mutu air limbah, sedangkan parameter Zn telah memenuhi baku mutu.

Gambar 4 menunjukkan bahwa peningkatan konsentrasi $\mathrm{HCl}$ pada saat proses pengasaman sludge menyebabkan jumlah ion $\mathrm{Fe}^{3+}$ yang terlarut semakin tinggi. Pada konsentrasi $\mathrm{HCl}$ yang tinggi kelarutan dari komponen $\mathrm{Fe}(\mathrm{OH})_{3}$ atau $\mathrm{Fe}_{2} \mathrm{O}_{3}$ di dalam sludge akan semakin tinggi (Mooheng dan Phenrat, 2018; Joshi et al., 2011). Konsentrasi ion $\mathrm{Fe}^{3+}$ terbesar diperoleh pada konsentrasi $\mathrm{HCl}$ sebesar $3 \mathrm{~N}$ yaitu sebesar $52,3 \mathrm{mg} / \mathrm{L}$. Hasil penelitian yang serupa juga dilaporkan oleh Joshi dan Shrivasta (2011) bahwa penggunaan metode pengasaman merupakan metode yang efektif untuk merecovery logam dari s/udge. Hasil penelitian tersebut berhasil merecovery logam Al dalam bentuk $\mathrm{Al}_{2}\left(\mathrm{SO}_{4}\right)_{3}$ di dalam sludge pada pH optimum 2,67 yang menghasilkan konsentrasi koagulan Al sebesar $361 \mathrm{mg} / \mathrm{L}$. Proses mekanisme reaksi recovery koagulan Fe dari sludge yang pada kondisi asam dapat dituliskan berdasarkan mekanisme persamaan reaksi (1) dan (2) (Li et al., 2009: 1432).

$$
\begin{aligned}
& \mathrm{Fe}(\mathrm{OH})_{3}+3 \mathrm{H}^{+} \rightarrow \mathrm{Fe}^{3+}+3 \mathrm{H}_{2} \mathrm{O} \\
& \mathrm{Fe}_{2} \mathrm{O}_{3}+6 \mathrm{H}^{+} \rightarrow 2 \mathrm{Fe}^{3+}+3 \mathrm{H}_{2} \mathrm{O}
\end{aligned}
$$

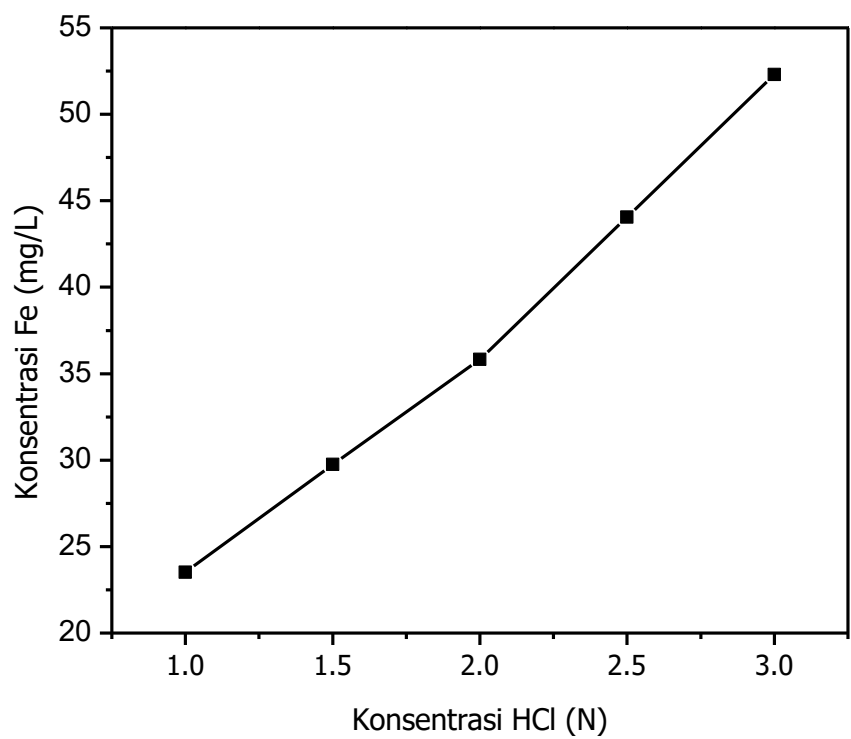

Gambar 4. Konsentrasi Koagulan Fe Pada Produk SRP Pada Variasi Konsentrasi HCl 
Gambar 5 menunjukkan bahwa pengaruh dosis koagulan SRP terhadap konsentrasi TSS air limbah setelah di uji dengan jar tes. Pada grafik tersebut menunjukkan bahwa meningkatkan dosis SRP pada air limbah menyebabkan terjadinya penurunan jumlah padatan yang tersuspensi (TSS). Tren penurunan parameter TSS air limbah tersebut berlaku pada semua koagulan SRP yang diasidifikasi pada konsentrasi $\mathrm{HCl} 1 \mathrm{~N}$ hingga $3 \mathrm{~N}$. Pada semua dosis SRP yang ditambahkan pada air limbah mampu menurunkan parameter TSS di bawah nilai baku mutu. Selain itu, SRP yang disintesis dari pengasaman sludge dengan konsentrasi $\mathrm{HCl} 3$ $\mathrm{N}$ akan menghasilkan penurunan TSS yang lebih besar dibandingkan dengan keempat produk SRP lainnya. Hal tersebut disebabkan konsentrasi SRP yang disintesis memiliki kandungan ion $\mathrm{Fe}^{3+}$ yang relatif lebih tinggi dibandingkan dengan produk SRP lainnya. Besarnya konsentrasi TSS terendah terjadi pada air limbah dengan penambahan koagulan SRP HCl $3 \mathrm{~N}$ pada dosis $10 \mathrm{~mL} / \mathrm{L}$ yakni sebesar $34 \mathrm{mg} / \mathrm{L}$. Pada kondisi tersebut diperoleh persen removal TSS sebesar 79,4\%. Mooheng dan Phenrat (2018) melakukan penelitian yang serupa yakni merecovery Fe dari sludge $\mathrm{Fe}(\mathrm{OH})_{3}$ menggunakan larutan $\mathrm{HCl}$ sebagai koagulan dalam pengolahan air limbah industri logam yang mengandung emulsi minyak. Hasil penelitian tersebut melaporkan bahwa penggunaan koagulan recovery dengan konsentrasi $\mathrm{FeCl}_{3} 2,25 \mathrm{mg} / \mathrm{L}$ menghasilkan efisiensi removal TSS tertinggi yakni sebesar $95,5 \%$. Hal yang sama dilaporkan oleh Suman et al. (2018: 218) bahwa asidifikasi sludge menggunakan asam pada konsentrasi $3 \mathrm{~N}$ mampu menghasilkan koagulan yang memberikan hasil yang terbaik dalam meremoval parameter kekeruhan di dalam air limbah dibandingkan dengan kondisi pengasaman pada konsentrasi lebih rendah dari $3 \mathrm{~N}$.

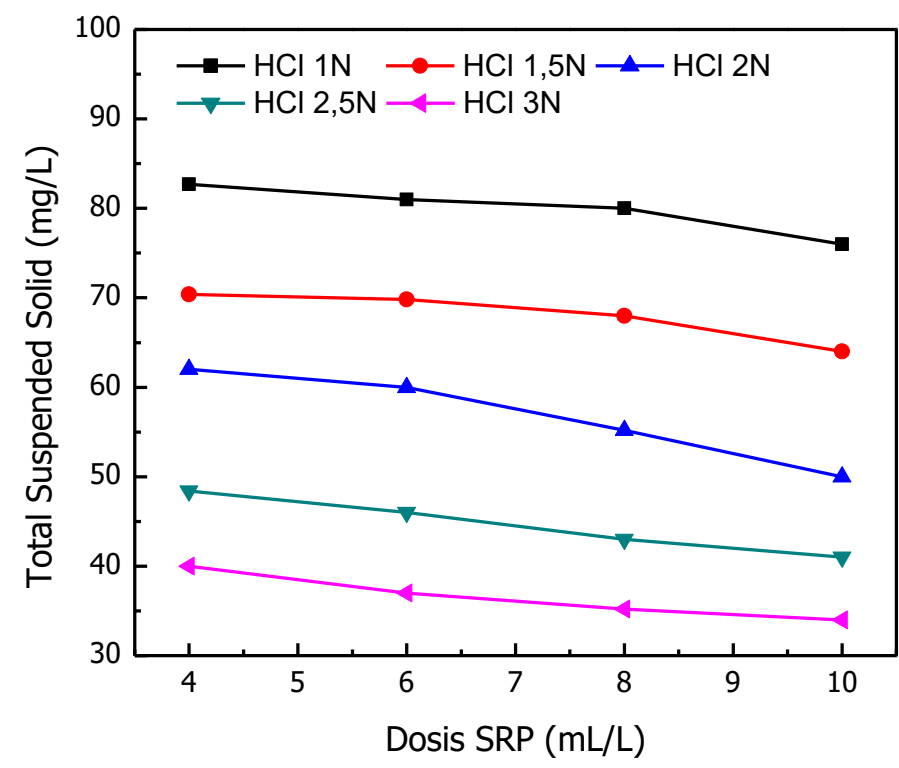

Gambar 5. Pengaruh Penambahan Koagulan SRP Terhadap Konsentrasi TSS

Ketika dilarutkan ke dalam air limbah koagulan SRP akan terionisasi menghasilkan ion $\mathrm{Fe}^{3+}$ yang berinteraksi dengan melekul $\mathrm{H}_{2} \mathrm{O}$ dengan reaksi sebagaimana pada persamaan (3) sampai dengan (5).

$\mathrm{Fe}^{3+}+\mathrm{H}_{2} \mathrm{O} \rightarrow \mathrm{FeOH}^{2+}+\mathrm{H}^{+}$

$\mathrm{FeOH}^{2+}+\mathrm{H}_{2} \mathrm{O} \rightarrow \mathrm{Fe}(\mathrm{OH})_{2}^{+}+\mathrm{H}^{+}$

$\mathrm{Fe}(\mathrm{OH})_{2}{ }^{+}+\mathrm{H}_{2} \mathrm{O} \rightarrow \mathrm{Fe}(\mathrm{OH})_{3} \downarrow+\mathrm{H}^{+}$ 


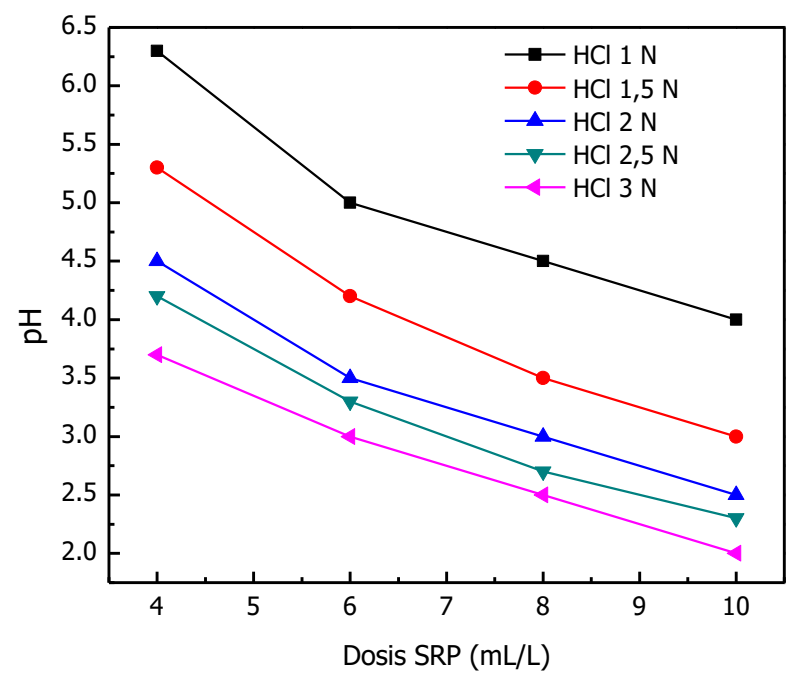

Gambar 6. Pengaruh Koagulan SRP Terhadap pH Air Limbah

Flok $\mathrm{Fe}(\mathrm{OH})_{3}$ yang terbentuk memiliki sisi aktif yang dapat menyerap partikel koloid sehingga TSS dari air limbah mengalami penurunan setelah penambahan SRP. Peningkatan dosis SRP mengarah pada terbentuknya inti flok yang lebih banyak sehingga jumlah partikel koloid penyebab kekeruhan yang diserap semakin tinggi (Suman et al., 2018; Subramonian et al., 2014). Dengan terbentuknya $\mathrm{Fe}(\mathrm{OH})_{3}$ maka proses destabilisasi koloid dapat terjadi melalui pemerangkapan partikel koloid yang tersuspensi di dalam air limbah. Keberadaan koagulan dapat menyebabkan terjadinya penetralan muatan sehingga gaya tolak-menolak antar partikel koloid yang bermuatan negatif akan hilang setelah terjadi adsorbsi oleh kation $\mathrm{Fe}^{3+}$. Gaya tarik van der Waals antar partikel koloid juga turut berperan dalam pembentukan aggregat menjadi lebih besar yang mengarah pada terjadinya sweep coagulation (Oriekhova et al., 2014; Wulan et al., 2010). Gambar 6 menunjukkan bahwa peningkatan dosis koagulan SRP dapat menyebabkan $\mathrm{pH}$ larutan menjadi lebih rendah. Pada $\mathrm{pH}$ koagulasi koagulasi yang rendah menyebabkan kepadatan muatan positif pada permukaan koagulan hidrolisat menjadi cukup tinggi. Hal ini menyebabkan netralisasi muatan dan reaksi hidrolisis ion Fe mendominasi mekanisme koagulasi sehingga pada titik isoelektrik menyebakan permukaan koloid bersifat netral sehingga mengarah pada peningkatan persen removal TSS (Chuan et al., 2010: 1384).

Gambar 7 menunjukkan pengaruh dosis koagulan SRP terhadap konsentrasi dari logam Fe setelah di uji dengan jar test. Pada grafik menunjukkan bahwa peningkatan dosis koagulan SRP cenderung menyebabkan konsentrasi Fe di dalam air limbah meningkat. Peningkatan tersebut berlaku untuk semua jenis SRP yang disintesis pada semua variasi konsentrasi $\mathrm{HCl}$ dalam kisaran $\mathrm{pH}$ 2-6,3. Hasil pengujian jar test menunjukkan bahwa SRP yang dibuat pada konsentrasi $\mathrm{HCl} 1 \mathrm{~N}$ menghasilkan konsentrasi Fe yang masih di bawah nilai baku mutu Fe. Selain itu, beberapa SRP yang disintesis dari $\mathrm{HCl}$ pada konsentrasi 1,5 $\mathrm{N}$ dan $2 \mathrm{~N}$ hanya dapat memenuhi nilai baku mutu pada dosis SRP $4 \mathrm{~mL} / \mathrm{L}$. Besarnya konsentrasi Fe terendah diperoleh pada dosis SRP $4 \mathrm{~mL} / \mathrm{L}$ dengan $\mathrm{HCl} 1 \mathrm{~N}$ yakni sebesar $0,137 \mathrm{mg} / \mathrm{L}$ yang memberikan persen removal Fe sebesar 97,5\%. Hasil penelitian menunjukkan bahwa penggunaan koagulan SRP yang disintesis pada konsentrasi $\mathrm{HCl}$ yang tinggi kurang direkomendasikan dalam proses removal kadar Fe. Hal tersebut disebabkan semakin besar konsentrasi $\mathrm{HCl}$ yang digunakan berpotensi menyebabkan $\mathrm{pH}$ air limbah menjadi lebih asam sehingga pH larutan menjadi cukup rendah. $\mathrm{pH}$ yang rendah yang menyebabkan muatan permukaan (potensial zeta) semakin positif sehingga terjadilah restabilisasi partikel koloid yang menolak ion Fe menjauhi permukaan sehingga Fe yang teremoval semakin rendah (Chuan et al., 2010; Padmavathy et al., 2016). 


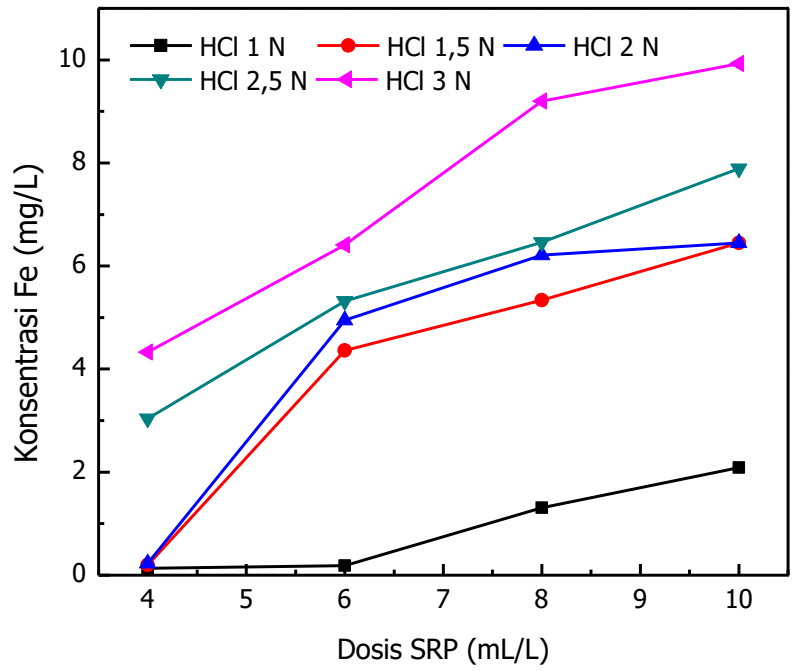

Gambar 7. Pengaruh Penambahan Koagulan SRP Terhadap Konsentrasi Fe

Gambar 8 menunjukkan bahwa konsentrasi Zn setelah dilakukan penambahan koagulan SRP. Hasil penelitian menunjukkan bahwa meningkatkan dosis SRP pada air limbah dapat menurunkan konsentrasi logam Zn yang terlarut di dalam air limbah. Hasil penelitian tersebut menunjukkan bahwa semakin rendah konsentrasi $\mathrm{HCl}$ yang digunakan pada recovery koagulan akan menghasilkan konsentrasi $\mathrm{Zn}$ semakin rendah yang mengarah pada penurunan konsentrasi Zn yang lebih tinggi. Pang et al. (2011) melaporkan bahwa kandungan logam Fe yang terlarut di dalam air limbah dapat meningkatkan proses removal $\mathrm{Zn}$ selama proses koagulasi-flokulasi. Hal tersebut disebabkan logam Fe dapat meningkatkan afinitas Zn pada permukaan flok $\mathrm{Fe}(\mathrm{OH})_{3}$ melalui proses adsorpsi sehingga proses removal $\mathrm{Zn}$ menjadi lebih tinggi. Hasil penelitiian ini melaporkan bahwa semua dosis SRP yang digunakan pada air limbah menghasilkan konsentrasi $\mathrm{Zn}$ dibawah $1 \mathrm{mg} / \mathrm{L}$ sehingga masih di bawah standar baku mutu. Penggunaan SRP HCl $3 \mathrm{~N}$ pada dosis $10 \mathrm{~mL} / \mathrm{L}$ menghasilkan parameter konsentrasi $\mathrm{Zn}$ yang terendah yakni sebesar 0,01 mg/L dengan persentase removal Zn sebesar 96,5\%.

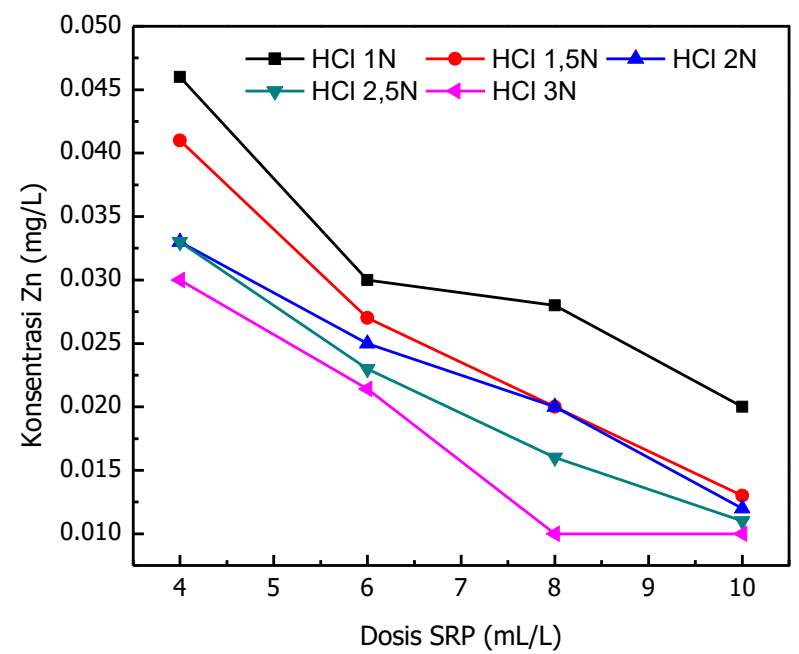

Gambar 8. Pengaruh Penambahan Koagulan SRP Terhadap Konsentrasi Zn

Hasil penelitian menunjukkan bahwa koagulan SRP yang berpotensi digunakan di perusahaan pembangkit listrik tenaga uap yakni yang dapat menurunkan TSS, kadar Fe, dan 
kadar Zn di bawah nilai baku mutu. Jenis dan dosis SRP yang dapat direkomendasikan untuk menurunkan TSS, kadar Fe, dan kadar Zn antara lain SRP $1 \mathrm{~N}$ dengan semua dosis yaitu $4 \mathrm{~mL} / \mathrm{L}, 6 \mathrm{~mL} / \mathrm{L}, 8 \mathrm{~mL} / \mathrm{L}, 10 \mathrm{~mL} / \mathrm{L}$ serta SRP 1,5 N dan SRP $2 \mathrm{~N}$ dengan dosis 4 $\mathrm{mL} / \mathrm{L}$. Oleh karena itu, berdasarkan penelitian tersebut s/udge koagulasi dapat direcovery menjadi sumber yang potensial sebagai koagiulan pada proses koagulasi air limbah. Hal tersebut dapat mengurangi volume sludge, menghemat biaya pembuangan, meminimalkan risiko lingkungan, dan kesehatan masyarakat.

\section{KESIMPULAN}

Penggunaan bahan kimia $\mathrm{FeCl}_{3} \cdot 6 \mathrm{H}_{2} \mathrm{O}$ sebagai koagulan pada WWTP PLTU pada umumnya menghasilkan limbah sludge dalam jumlah yang relatif besar. Hasil analisis gravimetri menunjukkan bahwa sludge yang telah dikeringkan memilki kandungan Fe sebesar $22,9 \%$ wt berpotensi untuk direcovery menghasilkan koagulan SRP yang mengandung $\mathrm{FeCl}_{3}$. Recovery logam Fe pada sludge dilakukan dengan asidifikasi menggunakan larutan $\mathrm{HCl}$ pada variasi konsentrasi $1-3 \mathrm{~N}$ dengan interval 0,5 $\mathrm{N}$. Hasil penelitian menunjukkan bahwa semakin tinggi konsentrasi $\mathrm{HCl}$ yang digunakan maka semakin tinggi konsentrasi Fe yang terecovery. Hasil pengujian air limbah dengan jar test menunjukkan bahwa peningkatan dosis koagulan SRP dapat menurunkan konsentrasi TSS dan Zn namun cenderung meningkatkan konsentrasi Fe yang terlarut. Besarnya konsentrasi TSS dan Zn terendah diperoleh pada kondisi koagulan SRP $3 \mathrm{~N}$ pada dosis $10 \mathrm{~mL} / \mathrm{L}$ yaitu masing-masing sebesar $34 \mathrm{mg} / \mathrm{L}$ dan 0,01 mg/L dengan persentase removal TSS sebesar 79,4\% dan Zn sebesar 96,5\%. Hasil penelitian menunjukkan bahwa jenis dan dosis SRP yang dapat menurunkan TSS, konsentrasi Fe, dan konsentrasi Zn yang masih memenuhi standar baku mutu antara lain semua dosis pada SRP $\mathrm{HCl} 1 \mathrm{~N}$, serta dua yang lain yakni SRP HCl 1,5 N dan SRP HCl $2 \mathrm{~N}$ dengan dosis koagulasi sebesar $4 \mathrm{~mL} / \mathrm{L}$.

\section{DAFTAR PUSTAKA}

Ahmad, T., Ahmad, K., Ahad, A., dan Alam, M. 2016. Characterization of Water Treatment Sludge and Its Reuse as Coagulant. Journal of Environmental Management 182: 606611.

Badan Pusat Statistik (BPS). 2014. Statistik Industri Manufaktur: Bahan Baku Raw Material. BPS Indonesia.

Chen, Z, Zhang, W.J., Wang, D.S., Ma, T., dan Bai, R.Y. 2015. Enhancement of Activated Sludge Dewatering Performance by Combined Composite Enzymatic Lysis and Chemical re-Flocculation with Inorganic Coagulants: Kinetics of Enzymatic Reaction and re-Flocculation Morphology. Water Research 83: 367-376.

Christensen, M.L., Keiding, K., Nielsen, P.H., dan Jorgensen, M.K. 2015. Dewatering in Biological Wastewater Treatment: A Review. Water Research 2: 14-24.

Chuan, C.B., Yu, G.B., Hua, X.C., dan Ying, F. 2010. Effects of Ph on Coagulation Behavior and Floc Properties in Yellow River Water Treatment Using Ferric Based Coagulants. Chinese Science Bulletin 55: 1382-1387.

Hach Chemical Company. 2010. DOC316.53.01145 Zincon and Iron Method. Hach Company. Washington, D.C.

Huang, S., Chen, J.L., Chiang, K.Y., dan Wu, C.C. 2010. Effects of Acidification on Dewaterability and Aluminum Concentration of Alum Sludge. Separation Science and Technology 45: 1165-1169. 
Joshi, S., dan Shrivastava, K. 2011. Recovery of Alum Coagulant from Water Treatment Plant Sludge: A Greener Approach for Water Purification. International Journal of Advanced Research 1: 101-103.

Keeley. J., Jarvis, P., Smith, A.D., dan Judd, S.J. 2016. Coagulant Recovery and Reuse for Drinking Water Treatment. Water Research 88: 502-509.

Li, L., Fan, M., Brown, R.C., Koziel, J.A., dan van Leuwen, J.H. 2009. Production of a New Wastewater Treatment Coagulant from Fly Ash with Concomitant Fue Gas Scrubbing. Journal of Hazardous Materials 162(2009): 1430-1437.

Mirwan, A. 2012. Pemanfaatan Kembali Limbah Padat Lumpur PDAM untuk Penjernihan Air dari Sungai Martapura Kalimantan Selatan. Jurnal Bumi Lestari 12(1): 77-84.

Moerdiyanti, M, Zahara, T.A., dan Jati, D.R. 2014. Penggunaan Tawas Cair Recovery dari Limbah Padat Lumpur PDAM Kota Pontianak Sebagai Koagulan untuk Pengolahan Air Bersih. Jurnal Teknologi Lingkungan Lahan Basah 1(1): 1-10.

Mooheng, P., dan Phenrat, T. 2018. Acid-Assisted Recycling Of $\mathrm{Fe}(\mathrm{OH})_{3}$ Sludge as Coagulant for Metalworking Fluid Wastewater Treatment. The NAXOS $20186^{\text {th }}$ International Conference on Sustainable Solid Waste Management Greece. 13-16 Juni: 1-10.

Muisa, N., Hoko, Z., dan Chifamb, P. 2011. Impacts of Alum Residues from Morton Jaffray Water Works on Water Quality and Fish, Harare, Zimbabwe. Phys. Chem. Earth Parts $A / B / C$ 36: 853-864.

Nair, A.T., dan Ahammed, M.M. 2015. The Reuse of Water Treatment Sludge as a Coagulant for Post-Treatment of UASB Reactor Treating Urban Wastewater. Journal of Cleaner Production 96: 272-281.

Oriekhova, O., dan Stoll, S. 2014. Investigation of $\mathrm{FeCl}_{3}$ Induced Coagulation Processes Using Electrophoretic Measurement, Nanoparticle Tracking Analysis and Dynamic Light Scattering: Importance of $\mathrm{Ph}$ and Colloid Surface Charge. Colloids and Surfaces A: Physicochem. Eng. Aspects 461: 212-219.

Padmavathy, K.S., Madhu, G, dan Haseena, P.V. 2016. A Study on Effects of Ph, Adsorbent Dosage, Time, Initial Concentration and Adsorption Isotherm Study for The Removal of Hexavalent Chromium (Cr (VI)) from Wastewater by Magnetite Nanoparticles. Procedia Technology 24: 585-94.

Pang, F.M., Kumar, P., Teng, T.T., Omar, A.K.M., dan Wasewar, K.L. 2011. Removal of Lead, Zinc and Iron by Coagulation-Flocculation. Journal of the Taiwan Institute of Chemical Engineers 42(5): 809-815.

Prakash, P., dan Sengupta, A.K. 2003. Selective Coagulant Recovery from Water Treatment Plant Residuals Using Donnan Membrane Process. Environmental Science and Technology 37: 4468-4474.

Sales, A, De Souza, F.R., dan Almeida, F.R. 2011. Mechanical Properties of Concrete Produced with a Composite of Water Treatment Sludge and Sawdust. Constr. Build. Mater. 25: 2793-2798.

Sari, G.L., Mizwar, A., dan Trihadiningrum, T. 2014. Pengolahan Limbah Bahan Berbahaya dan Beracun dari Industri Cat. Seminar Nasional Waste Management II. ITS Surabaya: 240250. 
Shak, K.P.Y., dan Wu, T.Y. 2015. Optimized Use of Alum Together with Unmodified Cassiaobtusifolia Seed Gum as a Coagulant Aid in Treatment of Palm Oil Mill Effluent Under Natural Ph of Wastewater. Ind. Crop. Prod. 76: 1169-1178.

Subramonian, W., Wu, T.Y., dan Chai, S.P. 2014. A Comprehensive Study on Coagulant Performance and Floc Characterization of Natural Cassia Obtusifolia Seed Gum in Treatment of Raw Pulp and Paper Mill Effluent. Industrial Crops and Products 61: 317324.

Suman, A., Ahmad, K., dan Haq, I. 2018. Water Treatment Plant Sludge Characterization, Recovery of Coagulant and Its Reuse. International Journal of Research in Engineering and Technology 7: 214-220.

Teh, C.Y., Budiman, P.M., Shak, K.P.Y., dan Wu, T.Y. 2016. Recent Advancement of Coagulation-Flocculation and Its Application in Wastewater Treatment. Ind. Eng. Chem. Res. 55: 4363-4389.

Teh, C.Y., dan Wu, T.Y. 2014. The Potential Use of Natural Coagulants and Flocculants in The Treatment of Urban Waters. Chem. Eng. Trans. 39: 1603-1608.

Trinh, T.K, dan Kang, L.S. 2011. Response Surface Methodological Approach to Optimize The Coagulation-Flocculation Process in Drinking Water Treatment. Chemical Engineering Research and Design 89: 1126-1135.

Wei, H., Gao, B., Ren, J., Li, A., dan Yang, H. 2018. Coagulation/Flocculation in Dewatering of Sludge: A Review. Water Research 143: 608-631.

Wulan, P.P., Dianursanti, D., Gozan, M., dan Nugroho, W.A. 2010. Optimasi Penggunaan Koagulan pada Pengolahan Air Limbah Batu Bara. Seminar Nasional Teknik Kimia Kejuangan. UPN Yogyakarta: F06-1-6.

Xu, G.R, Zhang, W.T., dan Li, G.B. 2005. Absorbent Obtained from CEPT Sludge in Wastewater Chemically Enhanced Treatment. Water Research 39: 5175-5185.

Xu, G.R., Yan, Z.C., Wang, Y.C., dan Wang, N. 2009. Recycle of Alum Recovered from Watertreatment Sludge in Chemically Enhanced Primary Treatment. J. Hazard. Mater. 161: 663-669. 